\title{
Evaluating some biochemical parameters after repeated orally administration of levofloxacin in male rats
}

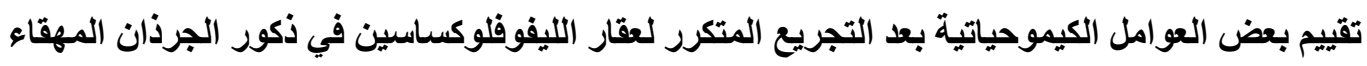

Wael. F. Al-Soufi

Falah Muosa Kadhim Al-Rekabi*

Department of Medical and Biological Supervision / Veterinary Directorate College of Veterinary Medicine / University of Baghdad*

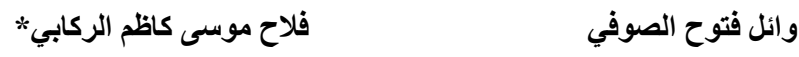

$$
\begin{aligned}
& \text { قسم الرقابة الدو ائية و الاحيائية /دائرة البيطرة } \\
& \text { كلية الطب البيطري / جامعة بغداد البادية }
\end{aligned}
$$

\begin{abstract}
This study was conducted to evaluate some biochemical parameters of levofloxacin in male rats. It was carried out on fifty four of the albino male rats, they were divided into three main groups equally and orally dosed levofloxacin and assigned as, the first group was dosed with the therapeutic dose $7.5 \mathrm{mg} / \mathrm{kg} / \mathrm{bw}$, the second group was dosed with the double therapeutic $\mathrm{dose} 15 \mathrm{mg} / \mathrm{kg} / \mathrm{bw}$, the third group was dosed with distilled water (negative control). The three groups were divided into three subgroups equally according to dosing period of 2 weeks, 4 weeks, 1 week after discontinuation of dosing. The results showed, there were significant $P<0.05$ increases in creatine kinase myocardial band of group 1 after 4 weeks of treatment and 1 week of levofloxacin withdrawal in comparison with control group, also there were significant $P<0.05$ increases in troponin-t of group 2 after 1 week of levofloxacin withdrawal in comparison with control group. While aspartate aminotransferase, total plasma protein, and creatinine levels showed significant $P<0.05$ increases and significant $P<0.05$ decreases in total plasma bilirubin level, but within normal limits, between experimental groups and control group. Whereas, there were no significant $\mathbf{P}>0.05$ changes in blood urea nitrogen levels between the experimental groups. We concluded that levofloxacin revealed minor toxic effects on organs tissue and most of these effects were reversible.
\end{abstract}

Keywords: Biochemical, Administration, Orally, Levofloxacin, Liver, Kidney, Heart, Male, Rat.

الملخص

أجريت هذه الاراسة لتقييم بعض العوامل الكيموحياتية لعقار الليفوفلوكساسين في ذكور الجرذان المهقاء.استخدم أربعة وخمسون

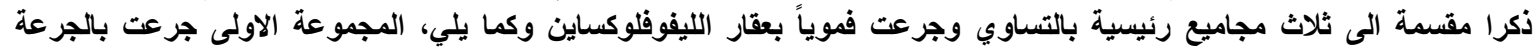

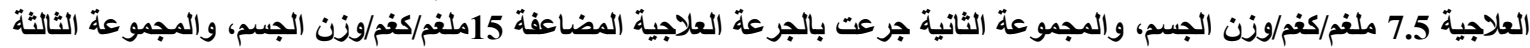

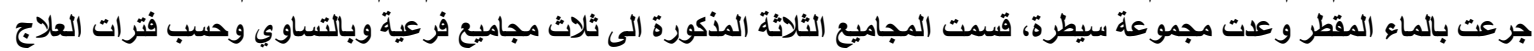
التي هي اسبوعين واربعة اسابيع وبعد اسبوع واحد من إيقاف العلاج. أظهرت النتائج أن هناك زيادة فيادة

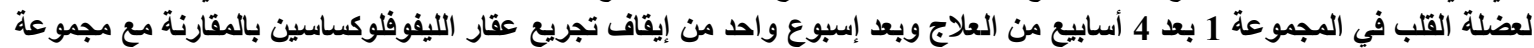

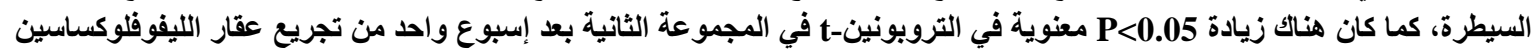

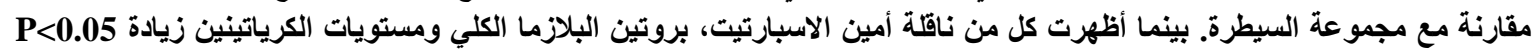

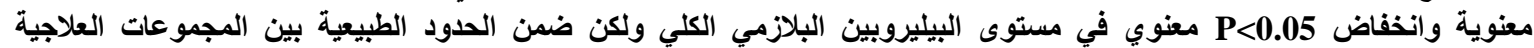

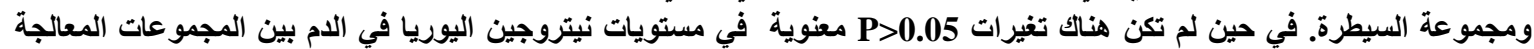

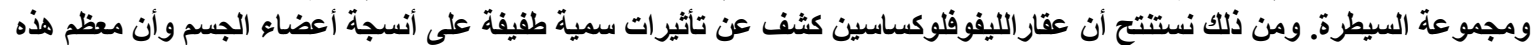




\section{Introduction}

The main fluoroquinlones active substances are cinoxacin, ciprofloxacin, enoxacin, flumequin levofloxacin, lomefloxacin, moxifloxacin, nalidixic acid, norfloxacin, ofloxacin, pefloxacin, pipemidic acid, prulifloxacin, and rufloxacin which are widely prescribed and are important for treating serious, life threatening bacterial infections for their specificity as broad spectrum antibiotics[1,2].

The main mechanism of action of levofloxacin and other fluoroquinolones antibacterials are the inhibition of DNA gyrase, which is an enzyme required for DNA replication, transcription, repair and recombination [3].

Levofloxacin is well distributed toward target body tissues, so it uses mainly in treatment of urinary tract infection and community-acquired pneumonia, including multidrug resistant strains of several bacteria [4].

Repeated administration of levofloxacin have been shown to cause arthropathy, Synovitis and articular cartilage lesions in immature dogs and juvenile rats [4] phototoxicity, central nervous system (CNS) stimulatory effects in mice and crystalluria has been observed in some intravenous rat studies [5].

Plasma alanine aminotransferase (ALT), aspartate aminotransferase (AST0, total plasma protein and total plasma bilirubin are reliable marker enzymes of liver function and integrity [6]. When body tissue or an organ such as the heart or liver is diseased or damaged, additional AST and ALT are released into the bloodstream. Increase in plasma ALT and AST has been reported in conditions involving necrosis of hepatocytes [7]. These enzymes, AST, alkaline phosphatase (ALP), and ALT, are diagnostic enzymes, and their release above normal physiological levels indicates a disease condition including various bone disorders and jaundice (ALP); viral hepatitis (ALT); and myocardial infarction (AST). The elevation in the activity of these enzymes by levofloxacin may be as a result of their release in response to tissue damage during routine normal destruction of erythrocytes, leukocytes, and other cells like liver cells [8].

Both urea and creatinine are metabolic waste products that are freely filtered by the glomeruli of the kidneys [9]. Serum/plasma concentrations are commonly used to screen for renal or cardiovascular diseases [10]. More so, plasma urea has been reported to increase in acute and chronic intrinsic renal disease and also when there is decreased effective circulating blood volume with decreased renal perfusion [11]. Elevation of the plasma levels of creatinine and urea by levofloxacin is an indication of abnormal renal function [12].

Creatine kinase-myocardial band has a lower basal level and a much narrower normal range. So, it is more sensitive marker of myocardial injury than total creatine kinase activity [13]. Also, releases of cardiac troponin-I (cTnI) as a biomarker of cardiac injuries induced by uses of fluoroquinolones [14].

Due to levofloxacin role in treatment on both human and animal diseases, this study was conducted to evaluate some biochemical parameters in male rats.

\section{Materials and Methods \\ Experimental Animal Housing}

54 healthy adult male rats were obtained from the National Center for Drug Control and Research (NCDCR) / Ministry of Health. Their ages ranged between $6-8$ months, and their weight ranged $500-$ $600 \mathrm{~g}$. They were kept under suitable environmental conditions of $20-25^{\circ} \mathrm{C}$. Food and water were offered, care was taken to avoid any unnecessary stress. The animals were kept for at least two weeks for adaptation before starting the experiment. Experiments of this study were conducted in the animal house and laboratories of the Department of the Medical and Biological Supervision / Veterinary Directorate.

\section{Experimental Design and Animal Grouping}

It was conducted under the approval of scientific committee of departments of Physiology, Biochemistry and Pharmacology / College of Veterinary Medicine/University of Baghdad and takes in consideration the standard ethic of animal welfare.

Fifty four male rats divided randomly and equally into three groups treated for 4 weeks as, with levofloxacin through gastric gavage and assigned as, group $1(\mathrm{G} 1)$ dosed therapeutic dose $7.5 \mathrm{mg} / \mathrm{kg} / \mathrm{bw}$, group 2 (G2) dosed $15 \mathrm{mg} / \mathrm{kg} / \mathrm{bw}$, while third group dosed distilled water and considered control group, furthermore each group subdivided into three subgroups equally according the period of exposure to levofloxacin which were included 2, 4 weeks of dosing and 1 week after discontinuing levofloxacin administration.

\section{Blood Sampling}

$5 \mathrm{ml}$ of blood was collected in heparinized tubes by heart puncture technique after rats got general anesthesia through intraperitonial (IP) injection with (Ketamine 100mg/kg/b.w and Xylazine 13mg/kg/b.w). Biochemical Tests 
Plasma blood urea nitrogen BUN concentration test was made by using Biosystem UREA/BUN-Color Kit (UREA/BUN - Color Urease/Salicylate) to measure BUN through detecting indophenol by spectrophotometry [15], plasma total proteins concentration test was made by using Biomaghreb total protein kit (Biuret Colormetric method) by detecting proteins to form a blue-violet complex with the copper salts in an alkaline medium (reaction of the biuret type) and measured it through spectrophotometry [16], plasma creatinine concentration test was made by using BioSystems creatinine kit (Creatinine JAFFE) to measure it concentration by spectrophotometry after creatinine reacts with alkaline picrate to produce a red colored complex [17], plasma total bilirubin level test was made by using Biomaghreb total and direct bilirubin kit, sulfanilic acid reacts with sodium nitrite to form diazotized sulfanilic acid with the presence of dimethylsulfoxide, total bilirubin reacts with diazotized sulfanilic acid to form azobilirubin and measured by spectrophotometry [18], aspartate aminotransferase (AST) was made by using AGAPPE SGOT kit and measured by spectrophotometry [19], Plasma Troponin T and Plasma Creatine Kinase myocardial band level tests were measured through ELISA, by using Rat CK-MB Isoenzyme [20] and Rat Tn - T (Troponin T) [21] ELISA Kits.

\section{Statistical analysis}

Analysis of variance and SAS (Statistical Analysis System - version 9.13). Two way ANOVA and Least significant differences (LSD) post hoc test were performed to assess significant differences among means. $\mathrm{P}<0.05$ was considered statistically significant [22].

\section{Results}

\section{1- Blood Urea Nitrogen BUN Concentration Level Values}

The results of BUN showed no significant $\mathrm{P}>0.05$ differences within all experimental groups along test periods. While the results of between experimental groups showed significant $\mathrm{P}<0.05$ increase after 2 weeks of levofloxacin dosing in G2 (levofloxacin $15 \mathrm{mg} / \mathrm{kg} / \mathrm{bw}$ ) when compared to G1 (levofloxacin $7.5 \mathrm{mg} / \mathrm{kg} / \mathrm{bw}$ ) but there was no significant $\mathrm{P}>0.05$ differences in comparison with the control group $\mathrm{C}$. And also there were no significant $\mathrm{P}>0.05$ differences observed after 4 weeks and withdrawal of levofloxacin dosing of both G1 and $\mathrm{G} 2$ in comparison with control group (C).(Table1).

Table 1. Plasma BUN Concentration (mg/dL) Level Values

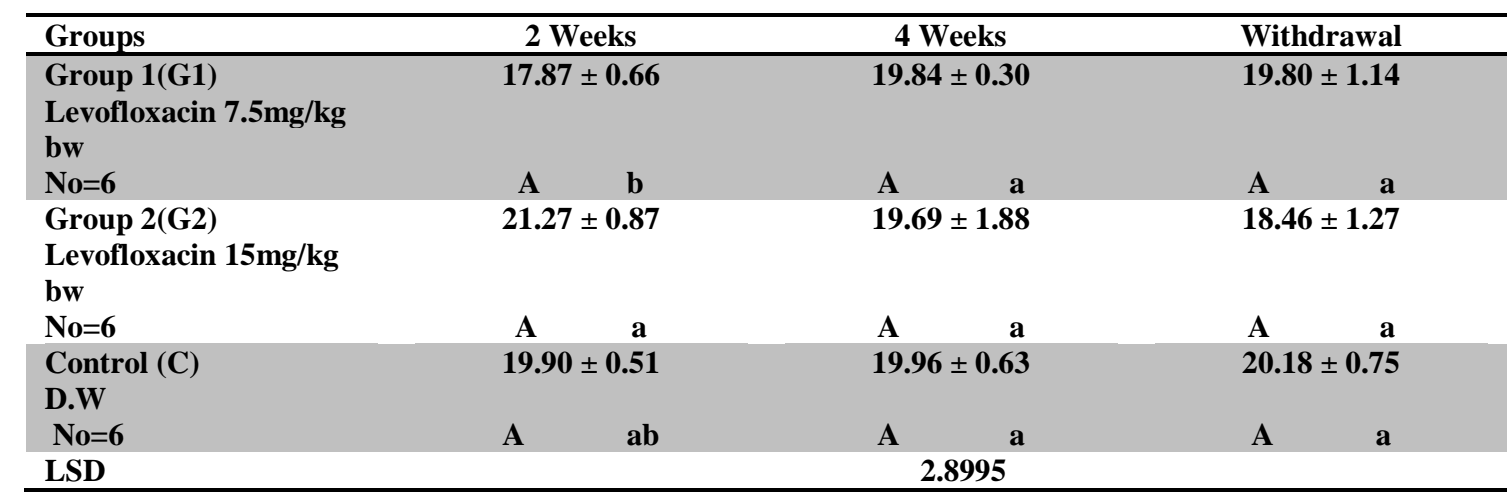

Values = mean \pm SE

Means with different capital letters denote significant differences $(\mathrm{P}<0.05)$ within group.

Means with different small letters denote significant differences $(P<0.05)$ between groups.

\section{2- Plasma Total Protein Concentration Level Values}

The results of total plasma protein showed, no significant $\mathrm{P}>0.05$ differences within experimental groups G2 (levofloxacin $15 \mathrm{mg} / \mathrm{kg} / \mathrm{bw}$ ) and control group $\mathrm{C}$, but there were significant $\mathrm{P}<0.05$ increases within G1(levofloxacin $7.5 \mathrm{mg} / \mathrm{kg} / \mathrm{bw}$ ) after 4 weeks and one week of levofloxacin dosing withdrawal compared with 2 weeks levofloxacin dosing, while the results between experimental groups G1, G2 and C showed significant $\mathrm{P}<0.05$ increase after 2 weeks of levofloxacin dosing in G2 compared with G1 whereas no significant $\mathrm{P}>0.05$ differences showed in control group $\mathrm{C}$ when compared with $\mathrm{G} 1$ and $\mathrm{G} 2$. But after 4 weeks and one week of levofloxacin withdrawal the results showed significant $\mathrm{P}<0.05$ increase in G1 compared with $\mathrm{C}$, but no significant $\mathrm{P}>0.05$ differences showed, in $\mathrm{G} 2$ when compared with G1and $\mathrm{C}$ groups. (Table2). 
Table 2. Plasma Total Protein Concentration (g/dL) Level Values

\begin{tabular}{|c|c|c|c|}
\hline Groups & 2 Weeks & 4 Weeks & Withdrawal \\
\hline $\begin{array}{l}\text { Group 1(G1) } \\
\text { Levofloxacin } 7.5 \mathrm{mg} / \mathrm{kg} \\
\text { bw }\end{array}$ & $5.83 \pm 0.69$ & $8.21 \pm 1.05$ & $8.36 \pm 0.59$ \\
\hline No $=6$ & B $\quad$ b & A & A \\
\hline $\begin{array}{l}\text { Group 2(G2) } \\
\text { Levofloxacin 15mg/kg } \\
\text { bw }\end{array}$ & $8.03 \pm 0.70$ & $7.36 \pm 0.77$ & $7.33 \pm 0.56$ \\
\hline $\mathrm{No}=6$ & A & A $\quad$ ab & ab \\
\hline $\begin{array}{l}\text { Control (C) } \\
\text { D.W }\end{array}$ & $6.86 \pm 0.43$ & $6.27 \pm 0.42$ & $6.43 \pm 0.23$ \\
\hline No $=6$ & ab & A $\quad$ b & $\mathbf{A}$ \\
\hline LSD & & $\mathbf{1 . 8 8 2 2}$ & \\
\hline
\end{tabular}

Values $=$ mean $\pm \mathrm{SE}$

Means with different capital letters denote significant differences $(P<0.05)$ within group.

Means with different small letters denote significant differences $(P<0.05)$ between groups.

\section{3- Plasma Creatinine Concentration Level Values}

The results of plasma creatinine showed, there were no significant $\mathrm{P}>0.05$ differences within experimental group $\mathrm{C}$, but there were significant $\mathrm{P}<0.05$ increase within $\mathrm{G} 1$ (levofloxacin $7.5 \mathrm{mg} / \mathrm{kg} / \mathrm{bw}$ ) after 4 weeks only, when compared with the values after 2 weeks, while the treated group G2 (levofloxacin $15 \mathrm{mg} / \mathrm{kg} / \mathrm{bw}$ ) showed, significant $\mathrm{P}<0.05$ decreases after 4 weeks in comparison with value after 2 weeks of levofloxacin dosing. After one week of levofloxacin withdrawal, both treated groups G1 and G2, showed no significant $\mathrm{P}>0.05$ difference in comparison with the values after 2 and 4 weeks. While the results of plasma creatinine level of between experiment groups, G1 showed, no significant P $>0.05$ changes after 2 weeks and one week of levofloxacin withdrawal, and significant $\mathrm{P}<0.05$ increase, after 4 weeks when compared to plasma creatinine level of control group, whereas plasma creatinine level of G2 showed, significant $\mathrm{P}<0.05$ increase after 2 weeks and no significant $P>0.05$ changes when after 4 weeks and 1 week of levofloxacin withdrawal when compared to the plasma creatinine level of control group.(Table3).

Table 3. Plasma Creatinine Concentration (mg/dL) Level Values

\begin{tabular}{|c|c|c|c|}
\hline Groups & 2 Weeks & 4 Weeks & Withdrawal \\
\hline $\begin{array}{l}\text { Group } 1(\mathrm{G1}) \\
\text { Levofloxacin } 7.5 \mathrm{mg} / \mathrm{kg} \\
\text { bw }\end{array}$ & $0.26 \pm 0.01$ & $0.42 \pm 0.03$ & $0.35 \pm 0.03$ \\
\hline $\mathrm{No}=6$ & bc & A & AB \\
\hline $\begin{array}{l}\text { Group 2(G2) } \\
\text { Levofloxacin 15mg/kg } \\
\text { bw }\end{array}$ & $0.39 \pm 0.06$ & $0.28 \pm 0.01$ & $0.32 \pm 0.03$ \\
\hline $\mathrm{No}=6$ & A $\quad \mathbf{a}$ & B bc & AB $\quad \mathbf{a}$ \\
\hline $\begin{array}{l}\text { Control (C) } \\
\text { D.W }\end{array}$ & $0.25 \pm 0.01$ & $0.29 \pm 0.02$ & $0.29 \pm 0.02$ \\
\hline $\mathrm{No}=6$ & $\mathbf{A}$ & A $\quad$ c & $\mathbf{A}$ \\
\hline LSD & & 0.0951 & \\
\hline
\end{tabular}

Values $=$ mean $\pm \mathrm{SE}$

Means with different capital letters denote significant differences $(P<0.05)$ within group.

Means with different small letters denote significant differences $(P<0.05)$ between groups.

\section{4- Plasma AST (Aspartate Aminotransferase) Level Values}

The results of plasma AST activity showed, there were significant $\mathrm{P}<0.05$ increase of plasma AST activity in both treated groups G1 $(7.5 \mathrm{mg} / \mathrm{kg} / \mathrm{bw}$ levofloxacin dosing) and G2 $(15 \mathrm{mg} / \mathrm{kg} / \mathrm{bw}$ levofloxacin dosing) after 4 weeks and one week after withdrawal of levofloxacin dosing in comparison with control group C, both groups G1 and G2 showed no significant P>0.05 changes in plasma AST activity after 2 weeks of treatment when compared to plasma AST activity of control group C. The plasma AST activity of within groups showed, that G1 after 4 weeks and one week after withdrawal of levofloxacin dosing, there were significant $\mathrm{P}<0.05$ increases when compared to the plasma AST values after 2 weeks of treatment, while $\mathrm{G} 2$ revealed significant $\mathrm{P}<0.05$ increases after 4 weeks of treatment in comparison to AST values after 
2 weeks of treatment, but the plasma AST values of G2 regain normal since the animals of this group revealed no significant $\mathrm{P}>0.05$ changes after one week of levofloxacin withdrawal when compared to the after 2 weeks values. No significant $\mathrm{P}>0.05$ changes showed, within control group along test period (Table4).

Table 4. Plasma AST Level (U/L) Values

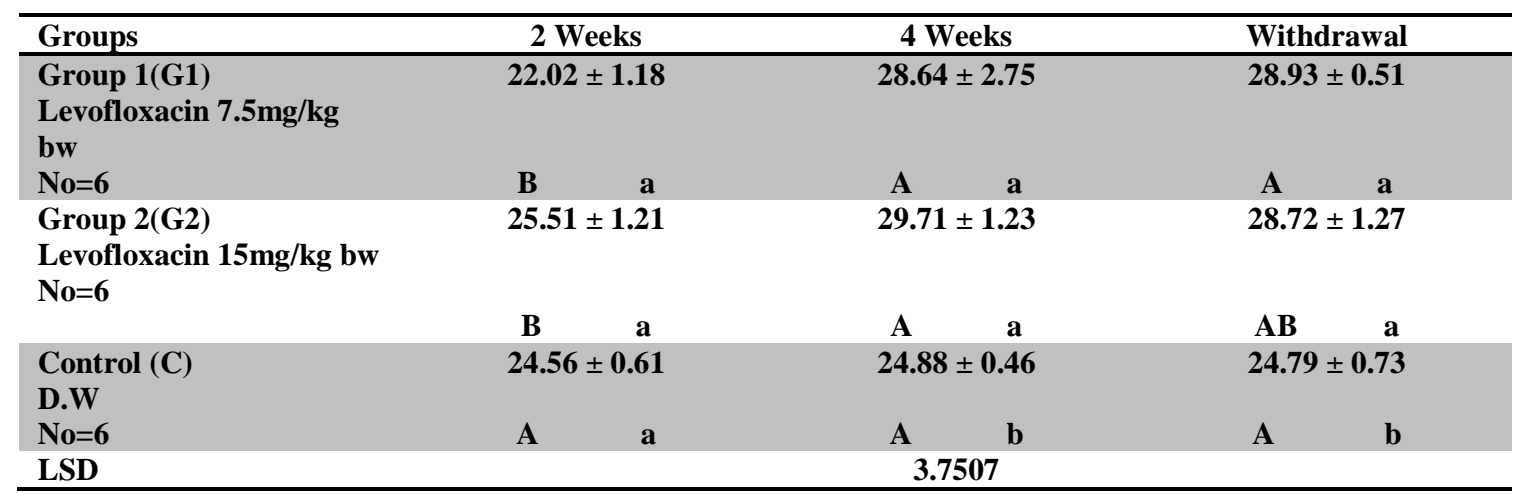

Values = mean $\pm \mathrm{SE}$

Means with different capital letters denote significant differences $(P<0.05)$ within group.

Means with different small letters denote significant differences $(P<0.05)$ between groups.

\section{5- Plasma Total Bilirubin Concentration Level Values}

The results of total plasma bilirubin levels within groups showed, significant $\mathrm{P}<0.05$ increase in $\mathrm{G} 1$ after one week of levofloxacin withdrawal in comparison with after 2 weeks and 4 weeks of treatment. While G2 showed, significant $\mathrm{P}<0.05$ decrease in total plasma bilirubin after one week of withdrawal of levofloxacin dosing in comparison with total plasma bilirubin after 4 weeks of treatment, but it was no significant $\mathrm{P}>0.05$ difference in comparison with its level after 2 weeks of levofloxacin dosing. While the results between groups showed, that after 2 weeks of levofloxacin dosing, both G1 $(7.5 \mathrm{mg} / \mathrm{kg} / \mathrm{bw})$ and G2 $(15 \mathrm{mg} / \mathrm{kg} / \mathrm{bw})$ reveled significant $\mathrm{P}<0.05$ decreases when compared with control group $\mathrm{C}$, while after 4 weeks of treatment that only G1 showed, significant $\mathrm{P}<0.05$ decrease in comparison with control group $\mathrm{C}$. After one week of levofloxacin withdrawal, only G2 registered significant $\mathrm{P}<0.05$ decrease in total plasma bilirubin level in comparison with the G1 and C groups. (Table5).

Table 5. Plasma Total Bilirubin Concentration (mg/dL) Level Values

\begin{tabular}{|c|c|c|c|}
\hline Groups & 2Weeks & 4Weeks & Withdrawal \\
\hline Group 1(G1) & $0.39 \pm 0.009$ & $0.42 \pm 0.01$ & $0.48 \pm 0.01$ \\
\hline \multicolumn{4}{|l|}{ Levofloxacin $7.5 \mathrm{mg} / \mathrm{kg}$ bw } \\
\hline & C & BC & A \\
\hline Group 2(G2) & $0.40 \pm 0.01$ & $0.47 \pm 0.01$ & $\mathbf{0 . 3 7} \pm \mathbf{0 . 0 1}$ \\
\hline \multicolumn{4}{|l|}{ Levofloxacin 15mg/kg bw } \\
\hline $\mathrm{No}=6$ & BC bc & $\mathbf{A} \quad \mathbf{a}$ & C $\quad$ b \\
\hline Control (C) & $0.51 \pm 0.04$ & $0.49 \pm 0.03$ & $0.50 \pm 0.02$ \\
\hline \multicolumn{4}{|l|}{ D.W } \\
\hline No $=6$ & $\mathbf{A}$ & $\mathbf{A}$ & $\mathbf{A}$ \\
\hline LSD & \multicolumn{3}{|c|}{0.0501} \\
\hline
\end{tabular}

Values $=$ mean \pm SE

Means with different capital letters denote significant differences $(P<0.05)$ within group.

Means with different small letters denote significant differences $(P<0.05)$ between groups.

\section{6- Plasma Creatine Kinase Myocardial Band (CK-MB) Level Values}

The results of plasma CK-MB activity within experimental groups G2 and C showed, there were no significant $\mathrm{P}>0.05$ differences along all the experimental periods, whereas within G1(levofloxacin $7.5 \mathrm{mg} / \mathrm{kg} / \mathrm{bw})$ after 4 weeks and after one week withdrawal of levofloxacin dosing showed, significant $\mathrm{P}<0.05$ decrease when compared to after 2 weeks of levofloxacin dosing. While the results between experimental groups showed there were no significant $\mathrm{P}>0.05$ differences between all experimental groups after 4 weeks and one week of withdrawal levofloxacin dosing periods, but only G1 showed, significant 
$\mathrm{P}<0.05$ increase in plasma CK-MB activity after 2 weeks of levofloxacin doing, in comparison with both G2 $(15 \mathrm{mg} / \mathrm{kg} / \mathrm{bw})$ and control group C (Table6).

Table 6. Plasma CK-MB Level (U/L) Values

\begin{tabular}{|c|c|c|c|}
\hline Groups & 2Weeks & 4Weeks & Withdrawal \\
\hline \multirow{2}{*}{$\begin{array}{l}\text { Group } 1(\mathrm{G} 1) \\
\text { Levofloxacin } 7.5 \mathrm{mg} / \mathrm{kg} \text { bw } \\
\text { No=6 }\end{array}$} & $3.00 \pm 0.05$ & $1.96 \pm 0.65$ & $1.96 \pm 0.43$ \\
\hline & $\mathbf{A}$ & B & B \\
\hline \multirow{2}{*}{$\begin{array}{l}\text { Group } 2(\mathrm{G2}) \\
\text { Levofloxacin } 15 \mathrm{mg} / \mathrm{kg} \text { bw } \\
\text { No=6 }\end{array}$} & $1.66 \pm 0.25$ & $2.14 \pm 0.25$ & $1.84 \pm 0.01$ \\
\hline & $\mathbf{A}$ & $\mathbf{A}$ & $\mathbf{A}$ \\
\hline \multirow{3}{*}{$\begin{array}{l}\text { Control (C) } \\
\text { D.W } \\
\text { No=6 }\end{array}$} & $1.88 \pm 0.02$ & $1.88 \pm 0.02$ & $1.87 \pm 0.01$ \\
\hline & & & \\
\hline & bc & A & A \\
\hline LSD & & 0.8404 & \\
\hline
\end{tabular}

Values = mean \pm SE

Means with different capital letters denote significant differences $(P<0.05)$ within group.

Means with different small letters denote significant differences $(\mathrm{P}<0.05)$ between groups.

\section{7- Plasma Troponin-T (Tn-T) Level Values}

The plasma Troponin-T level in both treated groups G1 $(7.5 \mathrm{mg} / \mathrm{kg} / \mathrm{bw})$ and G2 $(15 \mathrm{mg} / \mathrm{kg} / \mathrm{bw})$ showed, there were no significant $\mathrm{P}>0.05$ differences after 2 and 4 weeks of levofloxacin dosing, when compared to the plasma Tn-T level of control group C, but of one week of levofloxacin withdrawal, only G1 showed significant $\mathrm{P}<0.05$ increase in plasma Tn-T level, when compared to control group, while G2 showed no significant $\mathrm{P}>0.05$ changes. The within groups results of plasma Tn-T level showed, that G1 had significant $\mathrm{P}<0.05$ increase along the period of the experimental which obviously observed through the increasing of plasma Tn-T level after one week of levofloxacin withdrawal in comparison with the plasma Tn-T level after 2 and 4 weeks of levofloxacin dosing. Also G2 showed, significant $\mathrm{P}<0.05$ increases in plasma Tn-T level after 4 weeks of levofloxacin dosing and one week after levofloxacin withdrawal in comparison with plasma Tn-T level after 2 weeks of levofloxacin dosing. The control group $\mathrm{C}$ showed, no significant $\mathrm{P}>0.05$ changes in plasma Tn-T levels along the experimental periods (Table7).

Table 7. Plasma Troponin-T Concentration $(\mu \mathrm{g} / \mathrm{L})$ Level Values

\begin{tabular}{|c|c|c|c|}
\hline Groups & 2Weeks & 4Weeks & Withdrawal \\
\hline \multirow{2}{*}{$\begin{array}{l}\text { Group } 1(\mathrm{G} 1) \\
\text { Levofloxacin } 7.5 \mathrm{mg} / \mathrm{kg} \text { bw } \\
\mathrm{N}=6\end{array}$} & $0.39 \pm 0.03$ & $0.44 \pm 0.07$ & $0.92 \pm 0.05$ \\
\hline & C $\quad \mathbf{a}$ & BC $\quad$ a & $\mathbf{A} \quad \mathbf{a}$ \\
\hline \multirow{2}{*}{$\begin{array}{l}\text { Group } 2(G 2) \\
\text { Levofloxacin } 15 \mathrm{mg} / \mathrm{kg} \text { bw } \\
\mathrm{N}=6\end{array}$} & $0.33 \pm 0.03$ & $0.57 \pm 0.10$ & $0.45 \pm 0.04$ \\
\hline & B $\quad$ a & A & bc \\
\hline \multirow{2}{*}{$\begin{array}{l}\text { Control (C) } \\
\text { D.W, N=6 }\end{array}$} & $0.41 \pm 0.03$ & $0.42 \pm 0.02$ & $0.42 \pm 0.03$ \\
\hline & $\mathbf{A}$ & A & A \\
\hline LSD & & 0.1574 & \\
\hline
\end{tabular}

Values = mean \pm SE

Means with different capital letters denote significant differences $(P<0.05)$ within group.

Means with different small letters denote significant differences $(P<0.05)$ between groups.

\section{Discussion}

Blood tests are recommended to be conducted for indicative purposes. Different metabolic and other disorders that occur in the body may be detected in blood tests.

Everybody has its own specific enzymes, proteins or other organic molecules. As the blood system passes through all the organs, provides food to the cells and eliminates unnecessary and harmful products of the metabolism, any change in an organ(s) will be reflected in the blood circulation with the change in the concentration of enzymes, proteins, electrolytes, etc. 
Some of chemicals and pharmacological agents like acetaminophen and salicylates could cause liver toxicity as any form of liver disease. The vulnerability of liver toxicity depends on genetic predisposition, specific variation, age and systemic disease. Most of drug-induced liver toxicity are idiosyncratic (metabolic or a hypersensitivity) reaction and are dose dependent which it occurs at any time during exposure to a drug [23].

Hepatotoxicity that caused by fluoroquinolone is not well known. One of the main causes that researches refer to is formation of oxidative radicals, as a result of their metabolism by Cytochrome p 450 in the liver, which is lead to mitochondrial damage then affect RNA processing and transcription as well as inflammation serve to cause hepatotoxicity by fluoroquinolones [24,25]. Like what [26] found the uses of travofloxacinin in mice lead to hepatic mitochondrial peroxynitrite stress by formation of super oxide which is lead to mitochondrial damage and gene regulation.

Also, travofloxacin and other fluoroquinolones were found to enhance hepatotoxicity by cyclopropylamine substructure oxidation into reactive intermediates then leading to liver tissues damaging [27].

Mitochondrial damage which is caused by fluoroquinolone could be the main cause of necrotic and apoptotic hepatocellular death due to direct effect of these drugs on these organelles [28].

\section{Liver Injuries Biomarkers}

Olayinka, et.al. [29] found the administration effect of different doses of levofloxacin $(5,10$ and $20 \mathrm{mg} / \mathrm{kg} / \mathrm{b} . \mathrm{w}$ ) for seven days in twenty male wistar rats were significantly increased the plasma activities of ALP, ALT, and AST by $18 \%, 37 \%$, and $48 \% ; 45 \%, 58 \%$, and $67 \% ; 37 \%$, 43\%, and $57 \%$, respectively, when compared to the control. Also, there was a significant increase in plasma creatinine, urea, and total bilirubin in the treated groups relative to control groups. As compared with our result, the disagreement with this study may be referred to individual variation, or there were no withdrawal time could be measured to let them know if the liver functions return to its normal status.

Luis, et.al. [30] found the biochemical determinations in an 89-year-old woman was showed increase of aspartate aminotranferase: 958IU/L (normal; 6 to 32), alanine aminotransferase: 1261IU/L (N: 6 to 31), gamma-glutamil transpeptidase: $1126 \mathrm{IU} / \mathrm{L}$ (N: 5 to 36 ), and alkaline phosphatase: 77IU/L (N: 35 to 104). Bilurubin, level of albumin, and prothrombin time were normal. Use of levofloxacin was discontinued and 6 weeks later the liver function tests were back normal. Accordingly, our results was found agreed with this study and the highly elevation values in liver function could be referred to the species variation and the highly regeneration specification of the liver caused the return of liver functions to the normal status after the discontinues of levofloxacin administration, and this lead us that levofloxacin caused mild liver injures or inflammation

Patel, et.al. [31] found that repeated oral administration of levofloxacin $(10 \mathrm{mg} / \mathrm{kg} / \mathrm{bw})$ at 12 hours interval for 14 days in layer birds was safe based on evaluation of hematological parameters $(\mathrm{Hb}, \mathrm{PCV}$, TLC and DLC), blood biochemical parameters (AST, ALT, AKP, ACP, LDH, BUN, serum total protein, serum albumin, serum creatinine, blood glucose and total bilirubin). Levofloxacin could not be detected in body tissues (liver and skeletal muscle) at 12 hours after the last administration. Also, this study was agreed with our findings and the differentiation were noticed in total serum protein, this could be referred to species variation and severity of liver and kidney inflammation caused by levofloxacin due to the differentiation of experiment design.

Jun and Tisdale [32] found the elevation in $\gamma$-globulin is due to both acute and chronic liver disease which is lead to abnormality in serum proteins levels. In both acute and chronic hepatitis, the $\gamma$-globulin-levels are elevated (hypergammaglobulinæia) while the serum albumin level is normal or slightly decreased (hypoalbuminæmia). $\gamma$-globulins elevation will gradually return to normal levels after hepatitis subsides, this was obviously seen through our results in which plasma total protein values were gradually elevated in G1 along test periods and keeping with it significant $\mathrm{P}<0.05$ elevation in $\mathrm{G} 2$ along test periods in comparison with control groups. Accordingly, the effects of levofloxacin on plasma total protein could be dose and time dependent.

Teloh [33] found, the serum protein changes occurring in liver disease associated with parenchymal damage characteristically are decreased in serum albumin and increased in gamma globulin levels when the increasing in serum protein level regarding the increase in globulin not in albumin.

Accordingly, our results agreed with what [33] found in elevation of plasma total protein. We thought the increasing in IgM and IgG fractions (first response proteins) were due to liver inflammation cause by uses of levofloxacin along test periods.

Also, According to our results, we thought there were no elevation in plasma total bilirubin due to mild liver damaged that caused by uses of levofloxacin along test periods.

The increasing in plasma total protein in treated groups G1 and G2 thoughts to be due to elevation in globulins rather than albumin which it caused as response of inflammation by using of levofloxacin in two 
different concentration and this could be pronounced at prolonged administration of levofloxacin with high doses.

Shcherbinina [34] found that the bilirubin may go down as a result of taking some drugs or medications. This is especially true of certain medications that increase the metabolic rate of the liver (phenobarbital and other pain relievers).

\section{Kidney Injuries Biomarkers}

Creatinine and urea are often used as an indicator of renal function in mammals with elevations in both parameters being seen in the later stages of renal failure [14]. It is interesting to note that there is a statistically significant difference between the two locations groups studied here with the relict Norwegian group being greater than the Bavarian for both parameters. This is an important feature to note when attempting to interpret results in any renal health assessment. Values are similar to published values for nutria for creatinine but lower than nutria for urea [35].

Our results agreed with [31] who found that the repeated oral administration of levofloxacin $(10 \mathrm{mg} / \mathrm{kg} / \mathrm{bw})$ at 12 hours interval for 14 days in layer birds was safe based on evaluation of creatinine and BUN, and disagreed with [29] that found the administration effect of different doses of levofloxacin $(5,10$ and $20 \mathrm{mg} / \mathrm{kg} / \mathrm{b} . \mathrm{w}$ ) for seven days in twenty male wistar rats were significantly increased the plasma activities of creatinine and BUN.

According to our results of plasma creatinine and BUN level values, thought a mild damage occurs for kidney that leads to slight elevation, but within normal limits, in creatinine level with no changes of plasma BUN levels in comparison with control group.

Amin et.al. [36] found increases in serum creatinine level after mildly damaged kidneys, due to the glomerular filtration rate (GFR) being halved.

Blood urea nitrogen BUN is an indirect and rough measurement of renal and liver function. So, the elevation in blood urea nitrogen level means that the kidneys are not working very well due to congestive heart failure, urinary tract obstruction and certain type of medicines.

\section{Heart Injuries Biomarkers}

In acute myocardial infarction, commonly reported that CK-MB levels elevated in 4 to 6 hours then reach to the peak at 10 to 24 hours, and return to normal level within 3 to 4 days [13]. This was agreed with our results

John, et.al. [37] found an elevated of CK-MB without acute kidney injury after taking three doses of levofloxacin $750 \mathrm{mg}$ /daily in 52 years old man suffering from muscle tightness. But, CK-MB got back to normal value after stop of drug administration.

Paparoupa, et.al. [38] found in 70-year-old Caucasian male was treated with levofloxacin in a dosage of $500 \mathrm{mg}$, and after $8^{\text {th }}$ day cause an elevation of serum CK-MB level.

So, our result was found agreed with [23] and [38]

Girling, et.al. [35] found the effects of levofloxacin and ciprofloxacin on the cardiac mRNA expression of rat Kv4.3, Kv1.2 and Nav1.5 mRNAs were determined. Administration of the two antibiotics produced dose-dependent changes in ECG parameters that were more prominent in rats with AMI than healthy rats; this was accompanied by elevations in serum lactate dehydrogenase and creatine kinase-MB.

So we thought in our study findings, there was mild heart injuries were caused by uses of levofloxacin but it damaging were reversible after discontinued uses of levofloxacin.

Shahzadi, et.al. [14] found release of cardiac troponin-I (cTnI) as a biomarker of cardiac injuries induced by doxorubicin $(2.5$ and $15 \mathrm{mg} / \mathrm{kg} / \mathrm{b}$.w) alone and along with ciprofloxacin $(20 \mathrm{mg} / \mathrm{kg} / \mathrm{bw})$, following acute and chronic dose protocol in Sprague Dawley rats. All the treated groups, following acute or chronic dose protocol showed significant increase in cTnI plasma level from 137-248\% in comparison to control $(\mathrm{p}<0.001)$.

In our study that agreed with [14] showed animals after 1 week of levofloxacin withdrawal have evidence of slight elevation of inflammatory markers with necrosis in some myocytes which indicates that the elevation for troponin concentration might be of myocardial injury MI. According to these findings, we thoughts there were irreversible effect of levofloxacin on heart muscle which it caused in significant $\mathrm{P}<0.05$ increasing of plasma Tn-T level.

The main reason for performing this investigation was to address the role of rodent models in abnormal cTnT and CK-MB expression in heart muscle after uses of levofloxacin. The result of this study thoughts that TnT and CK-MB protein expression in heart muscle is unaffected by using of levofloxacin with therapeutic and double therapeutic doses. 


\section{Conclusion}

Our study revealed that levofloxacin had a minor biochemical parameters changes in treated groups along experiment periods which also revealed the minor effects on the body organs after taking levofloxacin according to dose and time manner.

\section{Acknowledgment}

Prays is to almighty Allah, the most merciful for giving me strength to accomplish this work. My deep gratitude should get to all members of Department of the Medical and Biological Supervision / Veterinary Directorate-IRAQ for their help and encouragement.

\section{References}

1. European Medicine Agency (2018). Public hearing on quinolones and fluoroquinolones, summary of safety concerns and list of questions. Science Medicines Health. An Agency of European Union. EMA / 166405.

2. Blessed, K., Dadah, A., Yussuf, M. and Uba, A.(2018). Quinolones resistant enteric bacteria isolated from hawked-zaki in selected parts of chicken local government area, Kaduna state Nigeria. Journal of Medical Toxicology, 4(1): 00085.

3. Bano, R., Arsalan, A., Ahmad, I. and Shad, Z. (2014). Levofloxacin: A potent antibiotic. Baqai Medical University, Baqai Institute of Pharmaceutical Sciences.

4. U.S. Food and Drug Administration. (2008). Levaquin prescribing information.

5. Afolabi, O. and Oyewo, E. (2014). Effects of ciprofloxacin and levofloxacin administration on some oxidative stress markers in the rat. International Journal of Biotechnology and Bioengineering, 8(1): 72 76.

6. Naik, S. and Panda, V. (2007). Antioxidant and hepatoprotective effects of Ginko biloba phytosomes in carbon tetrachloride induced liver injury in rodents. Journal of Liver International, 27(3): 393-399.

7. Pratt, D. and Kaplan, M. (2000). Evaluation of abnormal liver-enzyme results in a symptomatic patients. The New England Journal of Medicine, 342(17): 1266-1271.

8. Whitefield, J. (2001). Gamma glutamyl transferase. Journal Critical Reviews in Clinical Laboratory Sciences, 38(4): 263-455.

9. Johnson, D. (2011). "CKD screening and management overview" in handbook of chronic kidney disease management, D. John, ED., Chapter 4, Lippincott Williams and Wilkins.

10. Ferginson, M. and Waikar, S. (2012). Established and emerging markers of kidney function. Journal of Clinical Chemistry , 58(4): 680-689.

11. Stevens, L., Coresh, J., Green, T. and Levey, A. (2006). Assessing kidney function-measured and estimated glomerular filtration rate. New England Journal of Medicine, 354(1): 2473-2483.

12. Mouton, R. and Holder, K. (2006). Laboratory test of renal function. Journal of Anesthesia and Intensive Care Medicine, 7(7): 240-243.

13. Tomaszewski, M., Stepien, K., Tomaszewska, J. and Czuczwar, S. (2011). Stain-Induced myopathies. Pharmacological Reports: PR, 63(4): 859-866.

14. Shahzadi, A., Sonmez, I., Auahverdiyev, O., Onal, B., kandaz, C., Ozyazgan, S. Akkan, A. and Yazici, Z. (2014). Cardiac troponin-I(eTn-I) a biomarker of cardiac injuries induced by doxorubicin alone in combination with ciprofloxacin following acute and chronic dose protocol in Sprague dawley rats. International Journal of Pharmacology, 10(5): 258-266.

15. Higgins, C. (2016). Urea and creatinine concentration, the urea: creatinine ratio. Acute Care Testing Handbook, pages 1-8.

16. Nishi, H., Kestner, J. and Elin, J. (1985). Four method for determining total protein compared by using purified protein fractions from human serum. Journal of Clinical Chemistry, 13(1): 95-98.

17. Toora, B. and Rajagopal, G. (2002). Measurement of creatinine by jaffe's reaction-determining of concentration of sodium hydroxide required for maximum color development in standard, urine and protein free filtrate of serum. Indian Journal of Experimental Biology, 40(3): 52-54.

18. Chan, K., O’Connell, R., Sullivan, D., Hoffmann, L., Rajaman, K., Whiting, M., Donoghoe, M., Vanhala, M., Hamer, A., Yu, B., Stocker, R., Ng, M. and Keech, A. (2013). Plasma total bilirubin levels predict amputation events in type 2 diabetes mellitus: the finofibrate intervention and event lowering in diabetes (FIELD) study. Journal of Diabetologia, 56(4): 724-736.

19. Qian, X., Higgins, T. and Cembrowski, G. (2015). Limiting the testing of AST: A diagnostically nonspecific enzyme. American Journal of Clinical Pathology, 144(3): 423-426

20. Baird, M., Graham, S., Baker, J. and Bickerstaff, G. (2012). Creatine kinase-and exercise-related muscle damage implications for muscle performance and recovery. Journal of Nutrition and Metabolism, 2012, Article ID 960363, 13 pages.

21. Dubois-Deruy, E., Belliard, A., Mulder, P., Chwastyniak, M.; Beseme, O., Henry, J., Thuillaz, C., Amouyel, P., Richard, V. and Pinet, F. (2013). Circulating plasma serine ${ }^{208}$ - phosphorylated troponin-T 
levels are indicator of cardiac dysfunction. Journal of Cellular and Molecular Medicine, 17(10): 13351344

22. SAS (2010). SAS/STAT. User guide for personal computer. Release 9.13. SAS Institute, Inc., Cary, N.C., USA.

23. Karim, A., Ahmed, S., Rossoff, L., Siddiqui, and Steinberg, H. (2001). Possible levofloxacin -Induced acute hepatocellular injury in patient with chronic obstructive lung disease. Journal of Clinical Infectious Disease, 33(12): 2088-2090.

24. Labbe, G., Passayre, D., and Fromnty, B. (2008). Drug-Induced liver injury through mitochondria dysfunction: mechanisms and detection during preclinical safety studies. Journal of Fundamental of Clinical Pharmacology, 22(4): 335-353.

25. Yuain, L. and Kaplowitz, N. (2013). Mechanisms of drug-induced liver injury. Journal of Clinical Liver Dysfunction, 17(4): 507-518.

26. Hsiao, C., Younis, H. and Boelsterli, U. (2010). Trovafloxacin, a fluoroquinolone antibiotic with hepatotoxic potential, causes mitochondrial peroxynitrite stress in a mouse model of underlying mitochondrial dysfunction. Journal of Chemico-Biological Interaction, 188(1). 204-213.

27. Sun, Q. Zhu, R., Foss, F. and Mcdonald, T. (2008). Invitro metabolism of model cyclopropylamine to reactive intermediate: insights into trovafloxacin-induced hepatotoxicity. Chemical Research in Toxicology, 21(3): 711-719.

28. Jones, D., Lemustres, J., Han, D., Boelsterli, M. and Kaplowitz, N. (2010). Mechanism of pathogenesis in drug hepatotoxicity putting the stress on mitochondria. Journal of Molecular Intervention, 10(2): 198211.

29. Olayinka, E., Ore, A. and Ola, O. (2014). Influences of different doses of levofloxacin on antioxidant defense systems and makers of renal and hepatic dysfunction in rats. Journal of Advances in Toxicology, Vol. 2015 Article ID, 385023: 7 pages.

30. Luis, B., Muro, N., Cosme, A., Gueterez-stampa, U., Larzabal, M. and Arenas, J. (2007). LevofloxacinInduced acute hepatitis, Journal of Bronchology and Interventional Pulmonology, 14(1): 70-71.

31. Patel, J., Varia, R., Patel, U., Vihol, P., Bhavsar, S. and Thaker, A. (2009). Safety level of levofloxacin following repeated oral administration in white leg horn layer birds. Journal of Veterinary World, 2(4): 137-139.

32. Jun, T. and Tisdale, W. (1964). Serum gamma-globulins in acute and chronic liver disease. Journal of Nature, 201: 834-835.

33. Teloh, H. (1978). Serum proteins in hepatic disease. Annals of Clinical and Laboratory science, 8(2): 127-129.

34. Shcherbinina, M. (2007). Low blood bilirubin level: possible diagnostic and prognostic importance. Klinicheskaia Meditsina Journal, 85(10): 10-14.

35. Girling, S. Campbell-Palmer, R., Pizzi, R. Fraser, M., Cracknell, J., Arnemo, J. and Rosell, F. (2015). Haematology and serum biochemistry parameters and variations in the Eurasian Beaver (Castor Fiber). Journal Pone, 10(6): 1-13.

36. Amin, N., Mahmood, R., Asad, M., Zafar, M. and Raja, A. (2014). Evaluating urea and creatinine levels in chronic renal failure pre and post dialysis: a prospective study. Journal of Cardiovascular Disease, 2(2): 4 pages.

37. John, F., Oluronbi, R. and Pitchumoni, C. (2016). Levofloxacin-induced rhabdomyolysis: a case report. Journal of Medical Case Reports, 10(1): 235-237.

38. Paparoupa, M., Pietrzak, S. and Gillisen, A. (2014). Acute rhabdomyolysis associated with coadministration of levofloxacin and simvastatin in a patient with normal renal function. Case Report in Medicine, 4 pages. 